\title{
PENERAPAN ALGORITMA COLLISION DETECTION DAN BAYESIAN UNTUK STRATEGI MENYERANG JARAK DEKAT PADA NPC (NON PLAYER CHARACTER) MENGGUNAKAN UNITY 3D
}

\author{
Siti Asmiatun \\ Fakultas Teknologi Informasi dan Komunikasi Universitas \\ Semarang siti.asmiatun@usm.ac.id
}

\begin{abstract}
Game merupakan bidang ilmu yang semakin berkembang pesat dan sangat menarik untuk dipelajari karena memiliki potensi baik dari segi ilmu pengetahuan maupun dari segi komersil. Untuk menghasilkan game yang atraktif dan realistik, ada beberapa hal yang perlu diperhatikan. Salah satunya adalah memperhatikan strategi penyerangan khususnya untuk NPC (Non Player Character). Mengacu pada penelitian sebelumnya yang membahas tentang strategi menyerang jarak dekat untuk NPC (Non Player Character) [1]. Penelitian ini menggabungkan dua metode Collision Detection dengan bayesian untuk strategi menyerang jarak dekat. Dalam penelitian ini adalah membagi beberapa perilaku penyerangan NPC ketika berada pada posisi paling dekat dengan musuh. Penelitian ini menerapkan algoritma bayesian untuk klasifikasi perilaku penyerangan NPC dan algoritma collision detection untuk pengambilan keputusan perilaku ketika NPC menabrak player. Dengan penggabungan algoritma tersebut diharapkan dapat memperbaiki dari kelemahan penelitian sebelumnya. Klasifikasi penyerangan NPC dibiagi menjadi dua perilaku penyerangan yaitu perilaku smash dan perilaku kick. Sedangkan untuk variabel yang digunakan dalam klasifikasi bayesian adalah health point, attack point player dan jarak yang diperoleh dari kondisi NPC. Hasil penerapan metode collision detection dan bayesian ini membuktikan bahwa dengan metode collision detection NPC dapat mengambil keputusan perilaku menyerang meskipun berada pada jarak terdekat dengan player. Dari hasil pengujian metode dengan perhitungan confusion matrix mendapatkan akurasi sebanyak $90 \%$.
\end{abstract}

Keywords-game; klasifikasi; naive; bayes; strategi; menyerang; collision; detection

\section{PENDAHULUAN}

Game adalah kebutuhan dasar setiap manusia untuk menikmati hidup dan sebagai media pembelajaran [7]. Non Player Characters (NPC) merupakan bagian penting

di dalam sebuah game. Pemilihan aksi yang independen mampu membuat permainan menjadi lebih menarik. Namun, perilaku independen tanpa disertai dengan kecerdasan justru dapat mengurangi daya tarik permainan [2]. Untuk menghasilkan NPC yang lebih atraktif dan realistik dibutuhkan penerapan AI (Artificial Intellegence) kedalam NPC. Artifical Intelligence (AI) pada game FPS umumnya terdiri dari perencanaan path, mengambil item, menggunkan item, dan berperang [3]. Khusus untuk berperang NPC diharapkan mempunyai strategi-strategi khusus seperti halnya manusia [4][5].

Model strategi menyerang bisa bermacam-macam, misalnya strategi menyerang dengan memancing serangan musuh, kemudian pada kondisi tertentu perilaku berubah menjadi menghindar. Model strategi menyerang dalam sebuah game harus direncananakan untuk membuat game yang tidak membosankan bagi pemain [1].

Meninjau penelitian dari siti asmiatun dkk tentang strategi menyerang jarak dekat menggunnakan klasifikasi bayesian [1], terdapat beberapa kekurangan salah satunya adalah NPC didalam game tidak dapat menyerang musuh ketika berada pada posisi paling dekat dengan musuh dikarenakan collider NPC menyentuh collider player, sehingga mengakibatkan NPC terbang dan serangan NPC tidak fokus. Dari kekurangan penelitian tersebut, penelitian ini difokuskan untuk menerapkan penggabungan algoritma collision detection dan algoritma bayesian untuk startegi menyerang jarak dekat. Collision Detection bertujuan untuk mendeteksi adanya tabrakan atau serangan dari musuh, sehingga ketika jarak antara NPC dan player telah diklasifikasikan oleh bayesian untuk menyerang jarak terdekat, maka NPC dapat berperilaku yang sesuai dengan kondisinya. Pengembangan penelitian ini diharapkan dapat menghasilkan sebuah game yang menarik dengan akurasi yang lebih baik lagi dari penelitian sebelumnya.

\section{LANDASAN TEORI}

\section{A. NPC (Non Player Character)}

NPC (Non Player Character) adalah sebuah objek atau karakter dalam sebuah game yang dijalankan oleh komputer dan dapat berinteraksi dengan pemain game. NPC biasa disebut sebagai agen otonom karena termasuk karakter atau tokoh yang memiliki kemampuan untuk improvisasi tindakan 
dan perilaku mereka. Perilaku karakter yang otonom dapat dibagi menjadi tiga lapisan yang hirarkis seperti gambar dibawah ini :

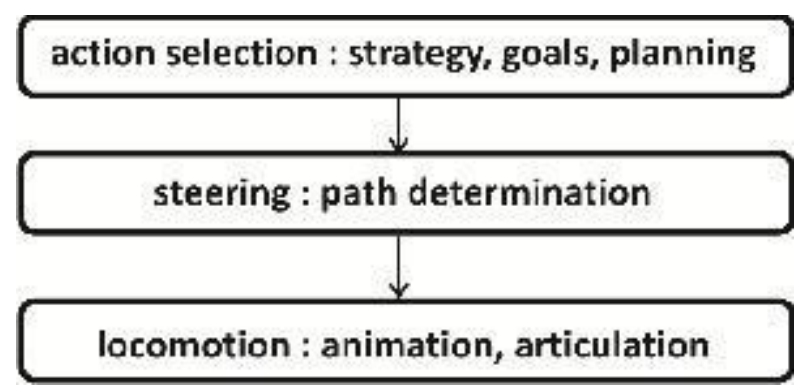

Gambar 2.1 Hirarki Gerak Perilaku

Gambar diatas menunjukkan pembagian perilaku karakter otonom menjadi tiga lapisan : seleksi tindakan, steering, dan penggerak. Pada penelitian ini difokuskan pada bagian action selection yang didalamnya berisi tentang strategi menyerang jarak dekat dengan collision detection dan klasifikasi bayesian [6].

\section{B. Naive Bayesian Classification}

Nä̈ve Bayes merupakan pengklasifikasian dengan metode probabilitas dan statistik yang dikemukakan oleh ilmuwan Inggris Thomas Bayes, yaitu memprediksi peluang di masa depan berdasarkan pengalaman di masa sebelumnya sehingga dikenal sebagai Teorema Bayes. Menurut Olson dan Delen (2008:102) menjelaskan Nä̈ve bayes untuk setiap kelas keputusan, menghitung probabilitas dengan syarat bahwa kelas keputusan adalah benar, mengingat vektor informasi obyek. Algoritma ini mengasumsikan bahwa atribut obyek adalah independen. Probabilitas yang terlibat dalam memproduksi perkiraan akhir dihitung sebagai jumlah frekuensi dari "master" tabel keputusan [9].

\section{Collision Detection}

Setiap permainan menerapkan collision detection (deteksi tabrakan), baik itu dalam hal tabrakan antara sprite dengan sprite maupun antara sprite dengan peluru dan lain-lain. Proses collision dapat dibagi menjadi dua kategori dasar, yaitu collision detection dan collision response, dengan jarak respon yang telah diaplikasikan secara spesifik. Terdapat banyak sekali jenis dari collision detection itu sendiri, pada gambar 2.11 merupakan tiga tipe dari collision detection [8].

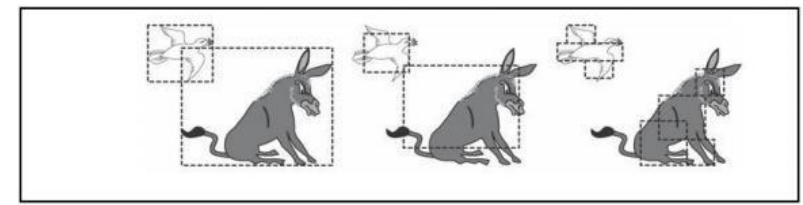

Gambar 2.2 Tipe Collision

Setiap objek diberi sebuah kotak sebagai acuan jika collision itu terjadi. Gambar pertama menunjukkan collision detection terjadi ketika objek burung bertabrakan dengan kotak yang memuat objek keledai, pada jenis collision detection ini rentan terhadap ketidaktelitian. Gambar kedua menunjukkan collision detection terjadi ketika kotak dari kedua objek tersebut bersinggungan. Jenis collision detection ini sudah lebih akurat dibanding jenis collision detection pada gambar pertama, namun untuk memilih faktor reduksi yang cocok itu sulit. Gambar ketiga menunjukkan collision detection terjadi ketika objek saling bersinggungan tanpa memperdulikan kotak secara keseluruhan.

\section{METODE PENELITIAN}

Metode penelitian yang digunakan untuk penelitian ini adalah dengan menggunakan penggabungan metode collision detection dan Bayesian. Seperti yang diilustrasikan dalam flowchart dibawah ini menjelaskan tentang tahap - tahap yang akan dilakukan dalam penerapan metode collision detection dan bayesian.

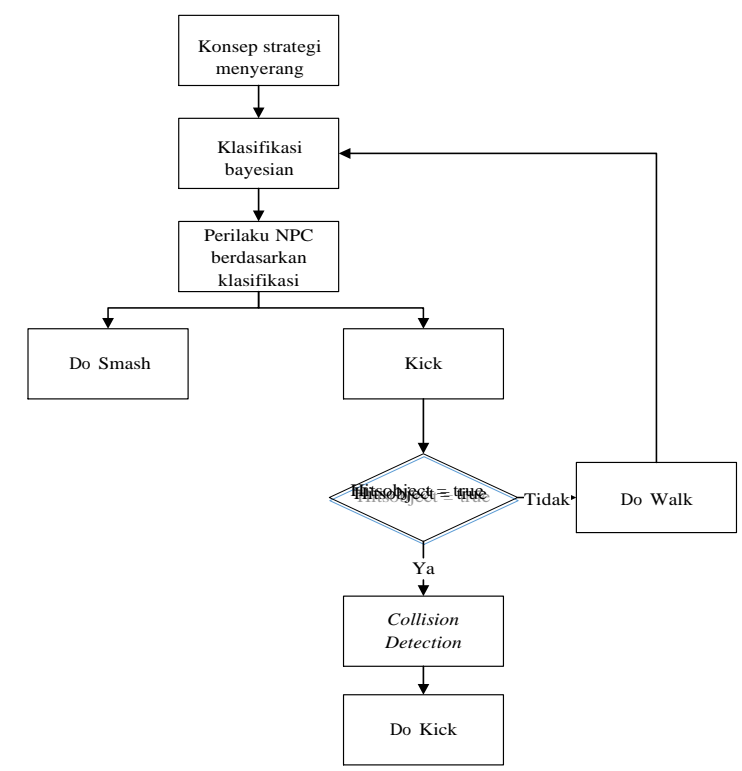

Gambar 3.1 Flowchart Metode Penelitian

\section{A. Perancangan Strategi Menyerang}

Penelitian ini akan menggunakan beberapa perilaku untuk strategi penyerangan yaitu perilaku Memukul dan Mengigit. Sedangkan parameter yang digunakan untuk menentukan perilaku adalah jarak, Health Point (HP) dan Attack Power player (APP) dari NPC, parameter dikelompokkan menjadi tiga kategori sebagai berikut:

Tabel 3.1 Kategori APP

\begin{tabular}{|l|l|}
\hline APP $>=0$ dan APP $<=1000$ & Lemah \\
\hline APP $>=1001$ dan APP $<=2000$ & Kuat \\
\hline
\end{tabular}

Tabel 3.2 Kategori HP

\begin{tabular}{|l|l|}
\hline $\mathrm{HP}>=0$ dan $\mathrm{HP}<=55000$ & kecil \\
\hline $\mathrm{HP}>=55001$ dan HP $<=114000$ & besar \\
\hline
\end{tabular}


Tabel 3.3 Kategori Jarak

\begin{tabular}{|c|c|}
\hline Jarak $>5.0$ & Jauh \\
\hline Jarak $<2.0$ & Dekat \\
\hline
\end{tabular}

Tabel 3.4 Rule penentuan perilaku

Jika APP kuat dan jarak jauh dan HP jauh maka smash

Jika APP kuat dan jarak jauh dan HP sedang maka smash

Jika APP kuat dan jarak dekat dan HP dekat maka kick

Jika APP kuat dan jarak dekat dan HP jauh maka kick

Jika APP lemah dan jarak jauh dan HP sedang maka smash

Jika APP lemah dan jarak jauh dan HP dekat maka smash

Jika APP lemah dan jarak dekat dan HP jauh maka kick

Jika APP lemah dan jarak dekat dan HP sedang maka kick

\section{B. Klasifikasi NPC (Non Player Character)}

Untuk menyusun strategi menyerang jarak dekat dengan klasifikasi bayesian membutuhkan dataset yang berupa status Attack Power, Jarak, Health Point dari NPC. Pada penilitian ini menggunakan dataset yang dihasilkan secara random. Berikut tabel dataset yang dibutuhkan untuk klasifikasi :

\begin{tabular}{|c|c|c|c|}
\hline $\begin{array}{l}\text { Attack Power } \\
\text { Player (DPP) }\end{array}$ & $\begin{array}{l}\text { Jarak } \\
\text { NPC }\end{array}$ & $\begin{array}{c}\text { Health } \\
\text { Point (HP) }\end{array}$ & Perilaku \\
\hline kuat & jauh & besar & smash \\
\hline kuat & dekat & besar & kick \\
\hline kuat & jauh & kecil & smash \\
\hline lemah & jauh & besar & smash \\
\hline kuat & dekat & besar & kick \\
\hline kuat & dekat & kecil & kick \\
\hline lemah & jauh & besar & $?$ \\
\hline
\end{tabular}

Dari dataset diatas, dapat dihitung dengan menggunakan teorema Bayes sebagai berikut :

$$
P\left(C_{i} \mid \boldsymbol{X}\right)=\frac{P\left(\boldsymbol{X} \mid C_{i}\right) P\left(C_{i}\right)}{P(\boldsymbol{X})} .
$$

Keterangan :

$\mathrm{P}\left(\mathrm{C}_{\mathrm{i}} \mid \mathrm{X}\right)=$ Probabilitas hipotesis $\mathrm{C}_{\mathrm{i}}$ jika diberikan fakta atau record $\mathrm{X}$ (Posterior probability)

$\mathrm{P}\left(\mathrm{X} \mid \mathrm{C}_{\mathrm{i}}\right)=$ mencari nilai parameter yang memberi kemungkinan yang paling besar (likelihood)
$\mathrm{P}\left(\mathrm{C}_{\mathrm{i}}\right)=$ Prior probability dari $\mathrm{X}$ (Prior probability $)$

$\mathrm{P}(\mathrm{X})=$ Jumlah probability tuple yg muncul

Jadi perhitungan yang dihasilkan dari teorema bayes diatas adalah :

Asumsi :

$\mathrm{Y}=$ Perilaku

$\mathrm{X} 1=\mathrm{APP}$

$\mathrm{X} 2$ = Jarak

$\mathrm{X} 3=\mathrm{HP}$

Dengan metode bayes dapat dihitung :

$\mathrm{P}(\mathrm{X} 1=$ Lemah, $\mathrm{X} 2=$ Jauh, $\mathrm{X} 3=$ Besar $\mid$ smash $)=$

$\{1 / 3.3 / 3 \cdot 2 / 3\} .3 / 6=1$

$\mathrm{P}(\mathrm{X} 1=$ Lemah, $\mathrm{X} 2=$ Jauh, $\mathrm{X} 3=$ Kuat $\mid$ kick $)=$ $\{0 / 3 \cdot 0 / 1 \cdot 2 / 1\} \cdot 3 / 6=0$

Sehingga menghasilkan table setiap perilaku sebagai berikut :

Tabel 3.6 Hasil klasifikasi bayesian

\begin{tabular}{|l|l|}
\hline \multicolumn{1}{|c|}{ Perilaku } & Hasil \\
\hline smash & 1 \\
\hline kick & 0 \\
\hline
\end{tabular}

\section{Penentuan Perilaku NPC (Non Player Character)}

Dalam menentukan perilaku harus berdasarkan dari nilai probabilitas perhitungan bayesian. Jika nilai probabilitas yang paling tinggi dimiliki oleh kategori smash maka perilaku NPC akan masuk kategori smash. Tapi jika nilai probabilitas yang paling tinggi dimiliki oleh kategori kick maka perilaku tidak akan memilih perilaku kick, melainkan perilaku akan mengecek sesuai dengan metode collision detection, apakah collider yang dimiliki NPC menyentuh collider player, jika collider NPC terbukti menyentuh collider player NPC akan mengambil keputusan untuk memilih perilaku kick.

\section{HASIL DAN PEMBAHASAN}

Sesuai dengan langkah-langkah pengembangan metode penelitian yang digunakan yaitu meliputi :

\section{A. Perancangan Finite State Machine (FSM)}

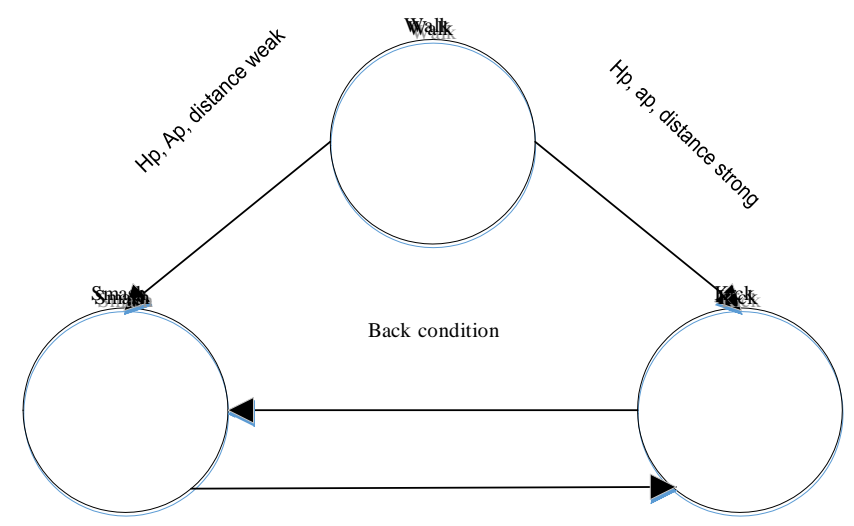

Gambar 4.1 Finite State Machine 
B. Pengumpulan Model Game (Material Collecting)

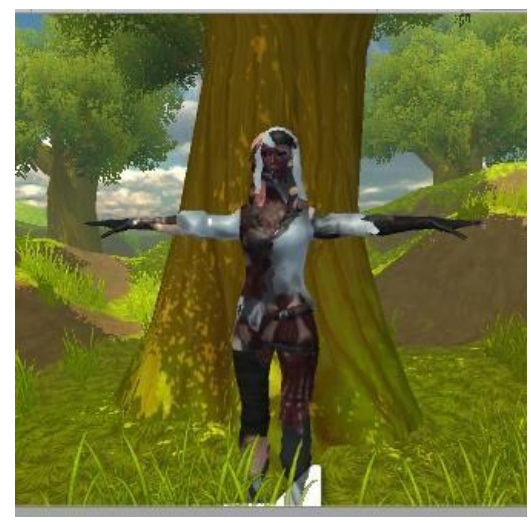

Gambar 4.2 Non Player Character

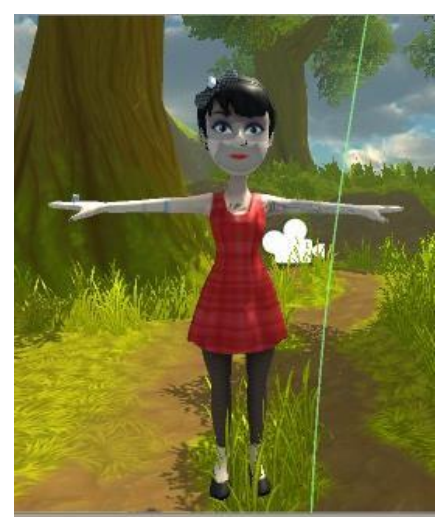

Gambar 4.3 Player

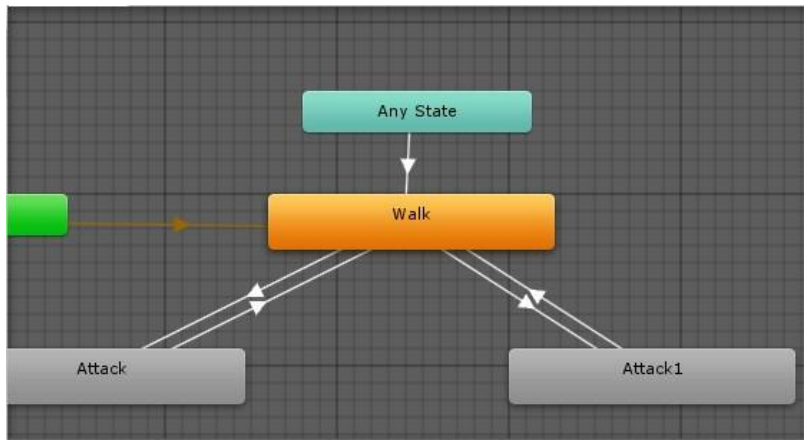

Gambar 4.4 Animation Control NPC

\section{Pembuatan Pengembangan Game (Assembly)}

Pada tahap ini, ada beberapa data training yang akan di implementasikan dengan formula bayesian.

1) Dataset

Tabel dibawah ini merupakan dataset yang akan diterapkan pada NPC. Dataset tersebut dapat dilihat pada tabel 4.3.

Tabel 4.1 Data training untuk klasifikasi bayes

\begin{tabular}{|c|c|c|c|}
\hline HP & Jarak & AP & Perilaku \\
\hline kuat & jauh & besar & smash \\
\hline kuat & dekat & Besar & kick \\
\hline
\end{tabular}

\begin{tabular}{|c|c|c|c|} 
kuat & jauh & kecil & smash \\
\hline lemah & jauh & besar & smash \\
\hline kuat & dekat & besar & kick \\
\hline kuat & dekat & kecil & kick \\
\hline
\end{tabular}

2) Modul AI Enemy

Pada tahap ini akan menjelaskan tentang bahasa pemrograman yang digunakan untuk menerapkan algoritma collision detection dan bayesian. Berikut flowchart script penerapan algoritma collision detection dan bayesian :

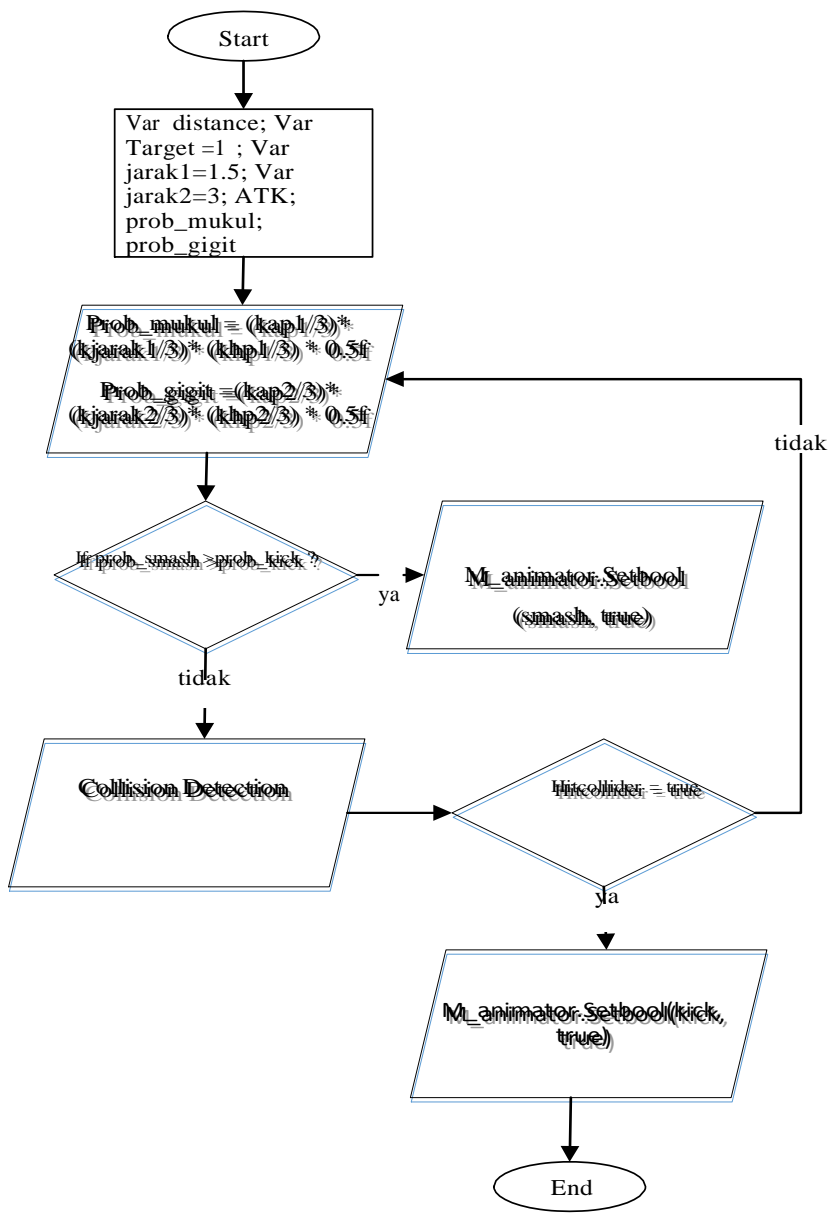

Gambar 4.5 Flowchart penggabungan metode

\section{Pengujian Skenario}

Pada tahap pengujian skenario, dibutuhkan sebuah rule yang digunakan untuk mengetahui ketepatan pengambilan keputusan perilaku yang dilakukan oleh NPC. Pengujian skenario bertujuan untuk menentukan kebenaran pengambilan keputusan perilaku. Rule tersebut ditentukan oleh developer game yang bisa dilihat pada tabel 3.1 sampai dengan tabel 3.4. 
Didalam metode bayesian yang berfungsi untuk mengklasifikasikan perilaku NPC, dibutuhkan perbandingan nilai probabilistik perilaku satu dengan nilai probabilistik lainnya. Jadi kondisi tersebut bisa dikatakan diterima jika :

Tabel 4.2 Kondisi yang diterima

\begin{tabular}{|l|l|l|}
\hline Kondisi 1 & Kondisi 2 & Perilaku \\
\hline $\begin{array}{l}\text { Probabilitas } \\
\text { smash > } \\
\text { probabilitas kick }\end{array}=$ & Hitcollider = false & Smash \\
\hline $\begin{array}{l}\text { Probabilitas } \\
\text { smash } \\
\text { probabilitas kick }\end{array}=$ & Hitcollider = true & Kick \\
\hline
\end{tabular}

Tabel 4.3 Hasil validasi

\begin{tabular}{|c|c|c|c|c|}
\hline No. & Kondisi & Harapan & Realita & $\begin{array}{l}\text { Kesimpu } \\
\text { lan }\end{array}$ \\
\hline 1 & $\begin{array}{l}\text { Prob smash }=0.22 \\
\text { Prob kick }=0 \\
\text { collision }=\text { false }\end{array}$ & Smash & Smash & Valid \\
\hline 2 & $\begin{array}{l}\text { Prob smash }=0.11 \\
\text { Prob kick }=0 \\
\text { collision }=\text { false }\end{array}$ & Smash & Smash & Valid \\
\hline 3 & $\begin{array}{l}\text { Prob smash }=0 \\
\text { Prob kick }=0.33 \\
\text { collision }=\text { false }\end{array}$ & Idle & Kick & $\begin{array}{l}\text { Tidak } \\
\text { valid }\end{array}$ \\
\hline 4 & $\begin{array}{l}\text { Prob smash }=0.1 \\
\text { Prob kick }=0 \\
\text { collision }=\text { false }\end{array}$ & Smash & Smash & Valid \\
\hline 5 & $\begin{array}{l}\text { Prob smash }=0.23 \\
\text { Prob kick }=0 \\
\text { collision }=\text { false }\end{array}$ & Smash & Smash & Valid \\
\hline 6 & $\begin{array}{l}\text { Prob smash }=0 \\
\text { Prob kick }=0.33 \\
\text { collision }=\text { true }\end{array}$ & Kick & Kick & Valid \\
\hline 7 & $\begin{array}{l}\text { Prob smash }=0.12 \\
\text { Prob kick }=0 \\
\text { collision }=\text { false }\end{array}$ & Smash & Smash & Valid \\
\hline 8 & $\begin{array}{l}\text { Prob smash }=0 \\
\text { Prob kick }=0.111 \\
\text { collision }=\text { true }\end{array}$ & Kick & Kick & Valid \\
\hline 9 & $\begin{array}{l}\text { Prob smash }=0 \\
\text { Prob kick = } 0.31 \\
\text { collision }=\text { false }\end{array}$ & Idle & Kick & $\begin{array}{l}\text { Tidak } \\
\text { valid }\end{array}$ \\
\hline 10 & $\begin{array}{l}\text { Prob smash }=0.22 \\
\text { Prob kick }=0 \\
\text { collision }=\text { false }\end{array}$ & Smash & Smash & Valid \\
\hline 11 & $\begin{array}{l}\text { Prob smash }=0 \\
\text { Prob kick }=0.33\end{array}$ & Kick & Kick & Valid \\
\hline
\end{tabular}

\begin{tabular}{|c|c|c|c|c|}
\hline & collision $=$ true & & & \\
\hline 12 & $\begin{array}{l}\text { Prob smash }=0.33 \\
\text { Prob kick }=0 \\
\text { collision }=\text { false }\end{array}$ & Smash & Smash & Valid \\
\hline 13 & $\begin{array}{l}\text { Prob smash }=0.11 \\
\text { Prob kick }=0 \\
\text { collision }=\text { false }\end{array}$ & Smash & Smash & valid \\
\hline 14 & $\begin{array}{l}\text { Prob smash }=0 \\
\text { Prob kick }=0.33 \\
\text { collision }=\text { true }\end{array}$ & Kick & Kick & Valid \\
\hline 15 & $\begin{array}{l}\text { Prob smash }=0 \\
\text { Prob kick }=0.33 \\
\text { collision }=\text { true }\end{array}$ & Kick & Kick & Valid \\
\hline 16 & $\begin{array}{l}\text { Prob smash }=0.33 \\
\text { Prob kick }=0 \\
\text { collision }=\text { false }\end{array}$ & Smash & Smash & Valid \\
\hline 17 & $\begin{array}{l}\text { Prob smash }=0 \\
\text { Prob kick }=0.11 \\
\text { collision }=\text { true }\end{array}$ & Kick & Kick & valid \\
\hline 18 & $\begin{array}{l}\text { Prob smash }=0.22 \\
\text { Prob kick }=0 \\
\text { collision }=\text { false }\end{array}$ & Smash & Smash & Valid \\
\hline 19 & $\begin{array}{l}\text { Prob smash }=0 \\
\text { Prob kick }=0.44 \\
\text { collision }=\text { true }\end{array}$ & Kick & Kick & Valid \\
\hline 20 & $\begin{array}{l}\text { Prob smash }=0 \\
\text { Prob kick }=0.21 \\
\text { collision }=\text { true }\end{array}$ & Kick & Kick & Valid \\
\hline
\end{tabular}

\section{E. Pengujian Metode}

Dari tabel diatas, dapat disimpulkan dengan tabel confusion matrix dengan Class a dan Class b pada tabel confusion matrix berturut-turut menunjukkan class smash dan kick yaitu sebagai berikut :

Tabel 4.4 Contoh Confusion matrix

\begin{tabular}{|l|c|c|c|}
\hline \multicolumn{4}{c}{ Class $a=$ smash Class $b=$ kick } \\
\hline \multicolumn{4}{|c|}{ Clast Class } \\
\hline \multirow{2}{*}{$\begin{array}{l}\text { Actual } \\
\text { Class }\end{array}$} & Class $a$ & 10 & 0 \\
\cline { 2 - 4 } & Class $b$ & 8 & 2 \\
\hline
\end{tabular}

Berdasarkan hasil confusion matrix terlihat bahwa 10 record pada class a diprediksi tepat sebagai class a dan sebanyak 0 record diprediksikan tidak tepat sebagai class $b$. Selanjutnya, seluruh record pada class $b$ terdapat 2 record diprediksi tidak tepat pada class $a$ dan 8 record diprediksi tepat sebagai class $b$. Dari hasil tersebut dapat dihitung akurasinya sebagai berikut:

$$
10+8
$$

$$
\text { Akurasi } \quad \text { X } 100=90 \%
$$

$$
10+0+8+2
$$


Jadi dapat disimpulkan bahwa perhitungan persentase tingkat akurasi pada confusion matrix mencapai nilai persentase sebesar $90 \%$.

\section{F. Distribusi}

Pada tahap distribusi merupakan tahapan yang digunakan untuk membangun game kedalam sebuah aplikasi game yang sesuai dengan perngkat yang dibutuhkan. Berikut adalah gamabaran hasil dari game :

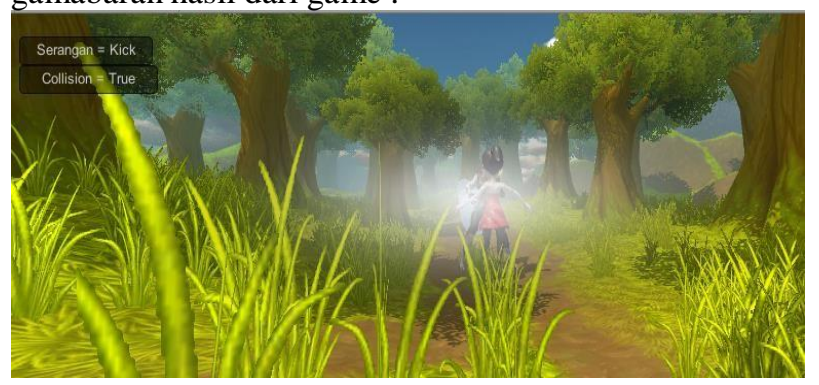

Gambar 4.6 Display Kick condition

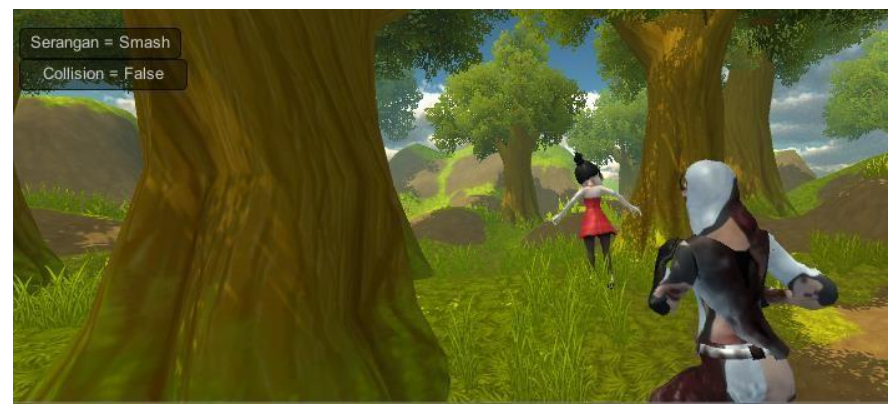

Gambar 4.7 Display Smash condition

\section{KESIMPULAN DAN SARAN}

Dari hasil penelitian ini dapat disimpulkan bahwa penggabungan dua metode collision detection dan bayesian dapat memperbaiki dari penelitian sebelumnya yaitu NPC didalam game tidak dapat menyerang musuh ketika berada pada posisi paling dekat dengan musuh dikarenakan collider
NPC menyentuh collider player. Hasil penerapan metode collision detection ini membuktikan bahwa dengan metode collision detection NPC dapat mengambil keputusan perilaku menyerang meskipun berada pada jarak terdekat dengan player. Dari hasil pengujian metode dengan perhitungan confusion matrix mendapatkan akurasi sebanyak 90\% ketepatan dalam pengambilan keputusan perilaku menyerang. Untuk pengembangan penelitian selanjutnya dapat ditambahkan perilaku menyerang pada NPC.

\section{DAFTAR PUSTAKA}

[1] Asmiatun dan Hendrawan. "Implementasi Klasifikasi Bayesian untuk strategi menyerang jarak dekat pada NPC (Non Player Character) Menggunakan Unity 3D".

[2] Hidayah, Muliadi dan Ridwan. " Algoritma Boids dan Logika Fuzzy Pada Pergerakan dan Perilaku Non Player Character Permainan Borneo Mission". Kumpulan Jurnal Ilmu Kopmuter. Volume 04, No.01. ISSN : 2406-7857. 2016.

[3] JinHyuk Hong dan Sung-Bae Cho. "Evolving Reactive NPCs for the Real-Time Simulation Game". CIG, 2005.

[4] Yunifa Miftachul Arif, Fachrul Kurniawan dan Fresy Nugroho. "Desain Perubahan Perilaku pada NPC Game Menggunakan Logika Fuzzy". National Seminar on Electrical, Informatics, and Its Education, 2011.

[5] McPartland M,and Gallagher M. "Creating a MultiPurpose First Person Shooter Bot With Reinforcement Learning “. IEEE Symposium on Computational Intelligence and Games, pp. 143-150,2008.

[6] Craig W. Reynolds. Steering Behaviors For Autonomous Characters. Sony Computer Entertainment America.

[7] Adams, E. Fundamental Of Game Design, 2nd Edition. Pearson Education, Inc, Berkeley. 2010

[8] Davison, Andrew. Killer Game Programming in Java. O'Reilly Media : Sebastopol. 2005

[9] D.L. Olson and D. Delen." Advanced data mining techniques”. Springer Verlag. ISBN3540769161. 2008. 